\title{
Heme oxygenase-1 alleviates advanced glycation end product-induced oxidative stress, inflammatory response and biological behavioral disorders in rat dermal fibroblasts
}

\author{
QINGLING LI $^{1 *}$, SHANGYAN LIANG $^{1 *}$, QIANWEI LAI ${ }^{1}$, LISHAN SHEN $^{2}$, YONG ZHANG $^{3}$ and RUOMI GUO ${ }^{2}$ \\ Departments of ${ }^{1}$ VIP Medical Service Center, ${ }^{2}$ Radiology and ${ }^{3}$ Nuclear Medicine, \\ The Third Affiliated Hospital, Sun Yat-Sen University, Guangzhou, Guangdong 510630, P.R. China
}

Received September 9, 2020; Accepted June 1, 2021

DOI: $10.3892 / \mathrm{etm} .2021 .10646$

\begin{abstract}
Advanced glycation end products (AGEs) are involved in delaying the wound healing of diabetic foot ulcers. The present study investigated the effects of heme oxygenase- 1 (HO-1) on oxidative stress, inflammatory insult and biological behaviors in rat dermal fibroblasts in the presence of AGEs. Rat dermal fibroblasts were cultured in the presence of AGEs $(100 \mu \mathrm{g} / \mathrm{ml})$, glucose $(1.0 \mathrm{~g} / \mathrm{l}$ or $4.5 \mathrm{~g} / \mathrm{l})$, hemin $(5 \mu \mathrm{M})$ and chromium mesoporphyrin (CrMP; $20 \mu \mathrm{M})$. A bilirubin kit, reverse transcription-quantitative PCR and western blotting were used to measure the activity and mRNA and protein levels of HO-1, respectively. ELISA kits were used to measure the levels of reactive oxygen species (ROS), malondialdehyde (MDA), 8-hydroxydeoxyguanosine (8-OHdG), TNF- $\alpha$, IL-6, IL-1 $\beta$ and the viability and collagen (hydroxyproline) secretion of fibroblasts. Cell proliferation and apoptosis were measured via flow cytometry. The scratch test was performed to evaluate cell migration. The results revealed that AGEs resulted in oxidative stress, inflammatory response and biological behavioral disorders in fibroblasts, while worsened functional disorders were caused by the combination of AGEs and high-glucose treatment. Hemin treatment induced sustained high HO-1 expression, decreased the levels of ROS, MDA, 8-OHdG, TNF- $\alpha$, IL-6, IL-1 $\beta$ and cell apoptosis, and increased cellular collagen synthesis, viability, proliferation and migration,
\end{abstract}

Correspondence to: Professor Ruomi Guo, Department of Radiology, The Third Affiliated Hospital, Sun Yat-Sen University, 600 Tianhe Road, Guangzhou, Guangdong 510630, P.R. China E-mail: guoruomi86@mail.sysu.edu.cn

Professor Yong Zhang, Department of Nuclear Medicine, The Third Affiliated Hospital, Sun Yat-Sen University, 600 Tianhe Road, Guangzhou, Guangdong 510630, P.R. China

E-mail:165551788@qq.com

${ }^{*}$ Contributed equally

Key words: advanced glycation end products, fibroblast, heme oxygenase-1, oxidative, inflammatory, biological behaviors whereas CrMP abolished the effects of hemin. It was observed that high HO-1 expression reversed the AGE-induced oxidative stress, inflammatory response and biological behavioral disorders in fibroblasts, but fibroblast function did not return to that observed under normal glucose levels. In conclusion, it was demonstrated that hemin treatment induced high HO-1 expression. HO-1 reduced the AGE-induced functional disorders in fibroblasts and may accelerate the healing of diabetic wounds by improving fibroblast biological behaviors and reducing the oxidative stress and inflammatory response.

\section{Introduction}

Diabetic patients are susceptible to the development of chronic wounds, especially on the feet (1). Diabetic foot ulcer (DFU)-derived fibroblasts contribute to defective matrices and chronic wound pathogenesis (1). Chronic hyperglycemia contributes to the formation of advanced glycation end products (AGEs), which are harmful compounds formed by glycation reactions and are considered to serve a causative role in the development and worsening of diabetic wound healing $(2,3)$.

Diabetes is a chronic condition associated with elevated oxidative stress and inflammation, involving a continuum of tissue and cellular insults that leads to the development of DFUs (4-6). Previous studies have demonstrated that the diabetic environment is characterized by elevated oxidative stress indices [reactive oxygen species (ROS), malondialdehyde (MDA) and 8-hydroxydeoxyguanosine (8-OHdG) $(4,5)]$ and increased proinflammatory cytokines, such as TNF- $\alpha$, IL- 6 and IL-1 $\beta$ (6,7). However, the human body possesses several defense mechanisms against oxidative stress and inflammatory insults. For example, heme oxygenase-1 (HO-1) is an antioxidative, anti-inflammatory and cytoprotective enzyme that is increased as a protective response to stress. It has been revealed that $\mathrm{HO}-1$ is upregulated in response to oxidative stress that leads to impaired wound healing (8). It has been indicated that $\mathrm{HO}-1$ exerted potent antidiabetic and insulin-sensitizing effects, in addition to suppressing immune/inflammatory insults (9). In a previous study, HO-1 improved the biological behavior of fibroblasts and reduced oxidative damage caused by a high-glucose (HG) 
environment (10). The present study examined HO-1 expression in rat dermal fibroblasts in experimental groups before and after the hemin induction of HO-1 expression to elucidate the antioxidative and anti-inflammatory effects of HO-1 and its cytoprotective role in high AGE environments.

\section{Materials and methods}

Cell culture and groupings. Rat dermal fibroblasts (cat. no. CRL-1213; American Type Culture Collection) were cultured in DMEM (Gibco; Thermo Fisher Scientific, Inc.) containing 10\% FBS (Gibco; Thermo Fisher Scientific, Inc.) without any supplementary antibiotics in an incubator $\left(37^{\circ} \mathrm{C} ; 5 \% \mathrm{CO}_{2}\right)$. Fibroblasts were cultured in DMEM containing $10 \%$ FBS under twelve different conditions (according to the groupings) for $72 \mathrm{~h}$ after $24 \mathrm{~h}$ of serum deprivation $(0.5 \% \mathrm{FBS})$. All manipulations were performed in dim lighting, and the plates were wrapped in aluminum foil to protect them from the light. Cells were sub-cultured after they had grown to confluence. All experiments were performed in triplicate.

The cells were divided into the following groups: i) normal glucose (NG) (NG 1.0 g/l; Gibco; Thermo Fisher Scientific, Inc.); ii) $\mathrm{NG}+$ Hemin (hemin $5 \mu \mathrm{M}$; MilliporeSigma); iii) $\mathrm{NG}+$ chromium mesoporphyrin (CrMP) $(\mathrm{CrMP} 20 \mu \mathrm{M}$; MilliporeSigma); iv) $\mathrm{NG}+$ Hemin + CrMP; v) AGEs + NG (AGEs $100 \mu \mathrm{g} / \mathrm{ml}$; Gibco; Thermo Fisher Scientific, Inc.); vi) $\mathrm{AGEs}+\mathrm{NG}+\mathrm{Hemin}$; vii) $\mathrm{AGEs}+\mathrm{NG}+\mathrm{CrMP}$; viii) $\mathrm{AGEs}+\mathrm{NG}+\mathrm{Hemin}+\mathrm{CrMP}$; ix $) \mathrm{AGEs}+\mathrm{HG}(\mathrm{HG}$ $4.5 \mathrm{~g} / \mathrm{l})$; $\mathrm{x}) \mathrm{AGEs}+\mathrm{HG}+\mathrm{Hemin}$; $\mathrm{xi}) \mathrm{AGEs}+\mathrm{HG}+\mathrm{CrMP}$; and xii) AGEs + HG + Hemin + CrMP group (9-11).

Determination of HO- 1 mRNA expression. Rat fibroblasts were cultured in 6-well plates at a density of $1.0-2.0 \times 10^{5}$ cells/well and harvested after $72 \mathrm{~h}$ of treatment. HO-1 mRNA expression was determined via reverse transcription-quantitative PCR. RNA extraction was performed using Trizol reagent (cat. no R0016; Beyotime Institute of Biotechnology) according to the manufacturer's guidelines. Then the M-MLV Reverse Transcriptase Kit (cat. no. MLV100K; ProFoldin) was used for the reverse transcription of RNA samples according to the manufacturer's guidelines. The primers were designed by Invitrogen (Thermo Fisher Scientific, Inc.), according to the sequences of rat HO-1 and EF2 in GenBank (http://www.ncbi.nlm.nih.gov/), as follows: HO-1 (forward, 5'-AGAGTCCCTCACAGACAGAGTTT-3' and reverse, 5'-CCTGCAGAGAGAAGGCTACATGA-3'); EF2 (forward, 5'-GACATCACCAAGGGTGTGCAG-3' and reverse, 5'-TCAGCACACTGGCATAGAGGC-3').

Amplification was performed according to the instructions of the SYBR PrimeScript RT-PCR Kit (cat. no. RR055A; Takara Bio, Inc.). Briefly, $10 \mu \mathrm{l}$ SYBR Premix Ex Taq ${ }^{\mathrm{TM}}(2 \mathrm{X})$, $0.4 \mu \mathrm{l}$ PCR forward primer $(10 \mu \mathrm{M}), 0.4 \mu \mathrm{l}$ PCR reverse frimer $(10 \mu \mathrm{M}), 0.4 \mu \mathrm{l}$ ROX reference dye (50X) and $2.0 \mu \mathrm{l} \mathrm{cDNA}$ template were added into a microfuge tube along with distilled water to make a total volume of $20.0 \mu \mathrm{l}$. The PCR reactions were performed in a LightCycler 480 real-time-PCR system (Roche Diagnostics), with denaturation at $95^{\circ}$ for $30 \mathrm{sec}$, followed by 40 cycles of $95^{\circ}$ for $5 \mathrm{sec}$ and $60^{\circ}$ for $20 \mathrm{sec}$. A melting curve analysis was performed to ensure the specificity of the amplification, and the products were quantified using the $2^{-\Delta \Delta \mathrm{Cq}}$ method (12). The difference between the $\mathrm{Ct}$ value of HO-1 and the corresponding EF2 value in each sample was used to determine the relative $\mathrm{HO}-1$ value $(10,11)$.

Determination of $\mathrm{HO}-1$ protein expression. HO-1 protein expression was measured using western blot analysis. Proteins were extracted from fibroblasts with $100 \mu$ l RIPA and $1 \mu 1$ PMSF (Beijing Solarbio Science \& Technology Co., Ltd.). The lysate centrifuged at $11,000 \mathrm{x}$ g for $20 \mathrm{~min}$ at $4^{\circ}$, and the supernatant was stored at $-80^{\circ}$. Protein concentrations were determined using a BCA kit (Beijing Solarbio Science \& Technology Co., Ltd.). A total of $40 \mu \mathrm{g}$ protein were electrophoresed in $10 \%$ denaturing SDS-PAGE. The proteins were transferred to PDVF membranes and incubated in blocking buffer [5\% nonfat milk in PBS containing $0.1 \%$ Tween 20 (PBS-T)] for $1.5 \mathrm{~h}$ at room temperature, followed by an overnight incubation at $4^{\circ} \mathrm{C}$ in 1:1,000 dilution of monoclonal antibody to HO-1 (cat. no. SAB5700731; Sigma-Aldrich; Merck KGaA). The membrane was PBS washed three times and incubated with a 1:1,000 dilution of horseradish peroxidase-linked goat anti-rabbit IgG (cat. no. SR134; Beijing Solarbio Science \& Technology Co., Ltd.) in PBS-T containing 1\% nonfat milk for $1.5 \mathrm{~h}$ at room temperature. Membranes were washed again and developed with a chemiluminescent agent (cat. no. SW2010; Beijing Solarbio Science \& Technology Co., Ltd.). The band densities were measured using TINA image software (Elysia-raytest $\mathrm{GmbH}$ ) (10).

Determination of HO-1 activity. HO-1 activity in fibroblast microsomes was measured using bilirubin generation based on the instructions of the bilirubin kit (cat. no. BS-E11055R2; Jiangsu Boshen Biological Technology Co., Ltd.). The level of extracted bilirubin was calculated based on the difference in absorption at $510 \mathrm{~nm}$ (extinction coefficient $40 / \mathrm{mmol} / \mathrm{cm}$ for bilirubin). HO-1 activity was expressed as pmol bilirubin $/ \mathrm{mg}$ protein/h, as previously reported (10).

Analysis of oxidative stress and inflammatory insult markers. Rat fibroblasts were cultured in 6-well plates at a density of $1.0-2.0 \times 10^{5}$ cells/well and the supernatants were collected after $72 \mathrm{~h}$ treatment. The levels of 8-OHdG (cat. no. E4442-100; BioVision, Inc.), ROS (cat. no. MS-21264R2; Shanghai Maisha Biological Technology Co., Ltd.), MDA (cat. no. KTE100650; Abbkine Scientific Co., Ltd.), TNF- $\alpha$ (cat. no. PT516; Beyotime Institute of Biotechnology), IL-6 (cat. no. ab100772; Abcam) and IL-1 $\beta$ (cat. no. ab100767; Abcam) were measured using ELISA according to the manufacturers' instructions and a plate reader (SpectraMax 340PC; Molecular Devices, LLC) $(4,7,10)$.

Collagen (hydroxyproline) secretion and viability assay. Rat fibroblasts were cultured in 6-well plates at a density of $1.0-2.0 \times 10^{5}$ cells/well. After treatment for $72 \mathrm{~h}$ as aforementioned, collagen (hydroxyproline) secretion was measured via ELISA. Hydroxyproline was measured according to the instructions of the rat hydroxyproline ELISA kit (cat. no. RTEB1742; Assay Genie). Cell viability was assessed using a CCK-8 kit (cat. no. ER0808; Wuhan Fine Biotech Co., Ltd.). The cells were inoculated into 96 -well plates at a 
density of 2.0-3.0x $10^{3}$ cells/well. Premixed CCK-8 reagent and complete cell culture medium (10 $\mu \mathrm{l}: 100 \mu \mathrm{l})$ was added into the 96-well plates, and the cells were incubated for 0.5-1 h at $37^{\circ} \mathrm{C}$, and $\mathrm{A} 450$ values were obtained subsequently with a 3550 automatic detector (Beckman Coulter, Inc.) $(10,13)$.

Proliferation and apoptosis assay. Rat fibroblasts were cultured in 6-well plates at a density of $1.0-2.0 \times 10^{5}$ cells/well and were harvested after $72 \mathrm{~h}$ of treatment as aforementioned. Cells were centrifuged at $11,000 \mathrm{x}$ g for $6 \mathrm{~min}$ at $4^{\circ} \mathrm{C}$, and the supernatant was discarded. Cells were resuspended with $1.5 \mathrm{ml}$ PBS. Subsequently, $300 \mu 1$ of the cell suspension was added into $800 \mu$ lice-cold ethanol, and fixed overnight at $4^{\circ} \mathrm{C}$ in dark. The next day, the cell suspension was centrifuged at $11,000 \mathrm{x} \mathrm{g}$ for $10 \mathrm{~min}$ at $4{ }^{\circ} \mathrm{C}$, and the supernatant was discarded. The cells were resuspended again with $500 \mu \mathrm{l}$ PBS containing RNase A (100 U/ml), and incubated for $30 \mathrm{~min}$ at $37^{\circ} \mathrm{C}$. Then, ethidium bromide $(2 \mathrm{mg} / \mathrm{ml})$ was added to a final concentration of $50 \mu \mathrm{g} / \mathrm{ml}$ and incubated for $30 \mathrm{~min}$ in dark at $4^{\circ} \mathrm{C}$. Cell cycle was detected by standard procedures of flow cytometry (FACSCalibur; BD Biosciences), and the S-phase cell ratio and proliferation index were calculated at the same time. S-phase cell ratio was calculated as $S /\left(G_{0} / G_{1}+S+\right.$ $\left.\mathrm{G}_{2} / \mathrm{M}\right)$, and proliferation index was calculated as $\left(\mathrm{S}+\mathrm{G}_{2} / \mathrm{M}\right) /$ $\left(\mathrm{G}_{0} / \mathrm{G}_{1}+\mathrm{S}+\mathrm{G}_{2} / \mathrm{M}\right)(10)$.

Cell apoptosis was assessed with Annexin V-fluorescein isothiocyanate (FITC)/propidium iodide (PI) Apoptosis Detection Kit (Beyotime Institute of Biotechnology) according to the manufacturer's guidelines. Briefly, cells were collected and then resuspended as aforementioned. Subsequently, $5 \mu 1$ AnnexinV-FITC and $5 \mu \mathrm{l}$ PI were added and maintained for $15 \mathrm{~min}$ in the dark at room temperature. Lastly, cell apoptosis was examined with a FACScan flow cytometry analyzer (BD Biosciences). The results were expressed as the mean \pm SD of three determinations per sample for each experiment, as previously reported (10).

Migration assay. Horizontal migration was assessed using the scratch test. Rat fibroblasts were cultured in 6-well plates at a density of 1.0-2.0x $10^{5}$ cells/well. After $72 \mathrm{~h}$ of treatment as aforementioned, the bottom of 6-well plates were scratched with a $10-\mu 1$ tip. Subsequently, the cells were cultured for $24 \mathrm{~h}$ without serum. Five different horizontal areas were selected and the width of the wound at 0 and $24 \mathrm{~h}$ after scratching was measured. The mean distance was the horizontal migration rate, which was calculated as follows: (Width at $0 \mathrm{~h}$-width at $24 \mathrm{~h}$ )/width at $0 \mathrm{~h} \times 100 \%$ (10).

Statistical analysis. Data are presented as the mean \pm SD. Comparisons between two groups were performed using unpaired Student's t-test. Pairwise comparisons among three groups were performed using one-way ANOVA followed by Student-Newman-Keuls post hoc analysis. Pairwise comparisons among $>3$ groups were performed using one-way ANOVA followed by Tukey's post hoc test. Data were analyzed with Microsoft Excel 2003 (Microsoft Corporation) and SPSS 13.0 (SPSS, Inc.) for Windows. Statistical analyses were performed using the average results of three experimental repeats under identical conditions. $\mathrm{P}<0.05$ was considered to indicate a statistically significant difference.

\section{Results}

Establishment of the fibroblast functional disorder model. Compared with normal glucose conditions, AGEs induced oxidative stress, inflammation and biological behavioral disorders in fibroblasts, and more severe cell damage was caused by the combination of AGEs and HG conditions.

ELISA was used to measure markers of oxidative stress (ROS, MDA and 8-OHdG) and inflammatory insult (TNF- $\alpha$, IL-6 and IL-1 $\beta$ ). ROS, MDA and 8-OHdG levels in the AGEs + NG group were 4.2-, 2.6- and 2.8-fold higher, respectively, compared with those in the NG group at $72 \mathrm{~h}$ (all $\mathrm{P}<0.05)$. ROS, MDA and 8-OHdG levels in the AGEs + HG group were 5.5-, 3.6- and 3.7-fold higher, respectively, compared with those in the NG group (all $\mathrm{P}<0.05$ ), and were 1.3-, 1.4- and 1.3-fold higher, respectively, in the AGEs + HG group compared with the AGEs + NG group (all $\mathrm{P}<0.05$ ) (Table I). TNF- $\alpha$, IL- 6 and IL-1 $\beta$ levels in the AGEs + NG group were 3.6-, 3.8- and 3.2-fold higher, respectively, compared with those in the NG group at $72 \mathrm{~h}$ (all $\mathrm{P}<0.05$ ). In the AGEs $+\mathrm{HG}$ group, TNF- $\alpha$, IL- 6 and IL-1 $\beta$ levels were 4.7-, 4.6- and 3.9-fold higher, respectively, compared with those in the NG group (all $\mathrm{P}<0.05$ ), and were 1.3-, 1.2 and 1.2-fold higher, respectively, in the AGEs + HG group compared with the AGEs + NG group (all $\mathrm{P}<0.05$ ) (Table I). These results indicated that AGEs caused oxidative stress and inflammatory insult in fibroblasts, and severe damage was caused by the combination of AGEs and $\mathrm{HG}$ conditions.

Subsequently, ELISA was used to measure fibroblast collagen secretion and viability. Cell proliferation and apoptosis were measured by flow cytometry, and the scratch test was used to evaluate cell migration. Fibroblast collagen secretion $(595.37 \pm 61.26 \mathrm{pg} / \mathrm{ml})$, viability $(1.46 \pm 0.18)$, the S-phase cell ratio $(14.93 \pm 1.97 \%)$, the proliferation index $(18.10 \pm 1.93 \%)$ and the horizontal migration rate $(0.47 \pm 0.12 \%)$ were inhibited in the AGEs + NG group compared with the NG group $(943.61 \pm 92.17 \mathrm{pg} / \mathrm{ml}, 1.87 \pm 0.21,23.67 \pm 2.67 \%, 29.14 \pm 2.55 \%$ and $0.73 \pm 0.19 \%$, respectively; all $\mathrm{P}<0.05)$. Early apoptosis $(9.87 \pm 1.99 \%)$ and end-stage apoptosis and death $(10.53 \pm 2.02 \%)$ were increased in the AGEs + NG group compared with the NG group $(4.36 \pm 1.42$ and $5.37 \pm 1.63 \%$, respectively; both $\mathrm{P}<0.05)$. Collagen secretion $(354.21 \pm 49.34 \mathrm{pg} / \mathrm{ml})$, cell viability $(1.09 \pm 0.17)$, the S-phase cell ratio $(12.00 \pm 1.67 \%)$, the proliferation index $(17.90 \pm 2.54 \%)$ and the horizontal migration rate $(0.28 \pm 0.11 \%)$ were inhibited in the AGEs + HG group compared with the NG group (all $\mathrm{P}<0.05$ ). Early apoptosis $(14.12 \pm 2.38 \%)$ and end-stage apoptosis and death $(20.72 \% \pm 4.18)$ were increased in the AGEs + HG group compared with the NG group (both $\mathrm{P}<0.05$ ). Collagen secretion, cell viability and migration rate were inhibited in the AGEs + HG group compared with the AGEs + NG group $(\mathrm{P}<0.05)$. Cell apoptosis rate was increased in the AGEs + HG group compared with the AGEs + NG group (both $\mathrm{P}<0.05$ ) (Table II) (Fig. 1). In the presence of AGEs, fibroblast collagen secretion, viability, proliferation and migration were decreased, and apoptosis was increased. Severe fibroblast biological behavioral disorders were caused by the combination of AGEs and HG conditions.

HO-1 expression in AGE-treated models. HO-1 expression exhibited time-dependent alterations and was the lowest at 
Table I. Oxidative stress and inflammatory injury index of fibroblasts under different conditions.

\begin{tabular}{|c|c|c|c|c|c|c|}
\hline Group & $\begin{array}{c}\text { ROS, } \\
\text { fluorescence } \\
\text { intensity }\end{array}$ & $\begin{array}{l}\mathrm{MDA}, \\
\mathrm{nmol} / \mathrm{ml}\end{array}$ & $\begin{array}{l}\text { 8-OHdG, } \\
\mathrm{ng} / \mathrm{ml}\end{array}$ & $\begin{array}{l}\text { TNF- } \alpha \\
\mathrm{pg} / \mathrm{ml}\end{array}$ & $\mathrm{IL}-6, \mathrm{pg} / \mathrm{ml}$ & $\mathrm{IL}-1 \beta, \mathrm{pg} / \mathrm{ml}$ \\
\hline NG & $214.03 \pm 24.91$ & $2.42 \pm 0.51$ & $2.99 \pm 0.62$ & $8.51 \pm 1.84$ & $10.56 \pm 2.13$ & $15.25 \pm 3.48$ \\
\hline $\mathrm{NG}+\mathrm{Hemin}$ & $135.73 \pm 12.42^{\mathrm{a}}$ & $1.59 \pm 0.23^{\mathrm{a}}$ & $1.41 \pm 0.20^{\mathrm{a}}$ & $3.48 \pm 0.82^{\mathrm{a}}$ & $4.71 \pm 0.82^{\mathrm{a}}$ & $6.59 \pm 1.97^{\mathrm{a}}$ \\
\hline NG + CrMP & $238.46 \pm 27.31$ & $2.68 \pm 0.65$ & $3.55 \pm 0.71$ & $10.72 \pm 1.98$ & $12.92 \pm 2.99$ & $18.65 \pm 4.09$ \\
\hline $\mathrm{NG}+\mathrm{Hemin}+\mathrm{CrMP}$ & $227.52 \pm 23.74$ & $2.51 \pm 0.42$ & $3.02 \pm 0.63$ & $9.13 \pm 1.79$ & $11.37 \pm 2.11$ & $16.99 \pm 4.31$ \\
\hline AGEs + NG & $892.48 \pm 50.27^{\mathrm{a}}$ & $6.27 \pm 0.78^{\mathrm{a}}$ & $8.39 \pm 0.85^{\mathrm{a}}$ & $30.81 \pm 4.63^{\mathrm{a}}$ & $39.88 \pm 5.97^{\mathrm{a}}$ & $48.85 \pm 6.27^{\mathrm{a}}$ \\
\hline AGEs + NG + Hemin & $485.32 \pm 38.64^{\mathrm{b}}$ & $3.98 \pm 0.71^{\mathrm{b}}$ & $3.22 \pm 0.72^{\mathrm{b}}$ & $11.56 \pm 2.01^{\mathrm{b}}$ & $21.96 \pm 3.63^{\mathrm{b}}$ & $23.26 \pm 5.24^{\mathrm{b}}$ \\
\hline AGEs + NG + CrMP & $917.60 \pm 62.84$ & $6.94 \pm 0.81$ & $9.78 \pm 0.96$ & $38.55 \pm 5.09$ & $42.42 \pm 6.56$ & $55.43 \pm 7.38$ \\
\hline $\begin{array}{l}\text { AGEs + NG + } \\
\text { Hemin + CrMP }\end{array}$ & $901.25 \pm 60.35$ & $6.68 \pm 0.79$ & $8.52 \pm 0.84$ & $32.79 \pm 5.11$ & $40.71 \pm 6.71$ & $52.83 \pm 7.50$ \\
\hline AGEs + HG & $1,183.73+79.37^{\mathrm{a}, \mathrm{b}}$ & $8.83 \pm 0.86^{\mathrm{a}, \mathrm{b}}$ & $10.97 \pm 1.23^{\mathrm{a}, \mathrm{b}}$ & $39.63 \pm 5.94^{\mathrm{a}, \mathrm{b}}$ & $48.68 \pm 7.02^{\mathrm{a}, \mathrm{b}}$ & $60.13 \pm 7.62^{a, b}$ \\
\hline AGEs + HG + Hemin & $582.16 \pm 41.38^{c}$ & $4.62 \pm 0.76^{c}$ & $5.63 \pm 0.88^{c}$ & $15.38 \pm 2.32^{\mathrm{c}}$ & $22.53 \pm 4.39^{c}$ & $32.86 \pm 5.89^{\mathrm{c}}$ \\
\hline $\mathrm{AGEs}+\mathrm{HG}+\mathrm{CrMP}$ & $1,294.31 \pm 83.65$ & $9.41 \pm 0.92$ & $12.85 \pm 1.40$ & $45.83 \pm 6.84$ & $52.50 \pm 7.58$ & $65.73 \pm 7.97$ \\
\hline $\begin{array}{l}\text { AGEs + HG + } \\
\text { Hemin + CrMP }\end{array}$ & $1,206.39 \pm 80.15$ & $8.96 \pm 0.83$ & $11.09 \pm 1.14$ & $42.09 \pm 6.58$ & $50.15 \pm 6.91$ & $62.92 \pm 7.25$ \\
\hline
\end{tabular}

Data are presented as the mean $\pm \mathrm{SD}(\mathrm{n}=3) .{ }^{\mathrm{a}} \mathrm{P}<0.05$ vs. $\mathrm{NG}$ group; ${ }^{\mathrm{b}} \mathrm{P}<0.05 \mathrm{vs}$. AGEs $+\mathrm{NG}$ group; ${ }^{\mathrm{c}} \mathrm{P}<0.05$ vs. AGEs $+\mathrm{HG}$ group. $\mathrm{NG}$, normal glucose; HG, high glucose; AGEs, advanced glycation end products; CrMP, chromium mesoporphyrin; ROS, reactive oxygen species; MDA, malondialdehyde; 8-OHdG, 8-hydroxydeoxyguanosine.

$72 \mathrm{~h}$ in the AGEs + NG and AGEs + HG group compared with the NG group (Fig. 2A). HO-1 mRNA levels, protein levels and protease activity decreased by 52.1, 61.6 and $44.7 \%$, respectively, at $72 \mathrm{~h}$ in the AGEs + NG group compared with the NG group (Fig. 2A, E, F and G; all $\mathrm{P}<0.05$ ), and were decreased by $67.5,80.2$ and $58.7 \%$, respectively, in the AGEs + $\mathrm{HG}$ group compared with the NG group (Fig. 2A, E, F and G; all $\mathrm{P}<0.05)$. HO-1 protein expression and protease activity decreased by 46.3 and $28.7 \%$, respectively, in the AGEs + HG group compared with the AGEs $+\mathrm{NG}$ group (both $\mathrm{P}<0.05$ ) (Fig. 2E-G). The results also demonstrated that hemin induced high HO-1 expression at least within $72 \mathrm{~h}$ of treatment (Fig. 2B-D). HO-1 mRNA expression, protein expression and protease activity in the NG + Hemin group were 9.9-, 9.7- and 10.1-fold higher, respectively, than those in the NG group at $72 \mathrm{~h}$ (Fig. 2B, E, F and H; all $\mathrm{P}<0.05$ ), were 9.0-, 10.5- and 9.2-fold higher, respectively, in the AGEs + NG + Hemin group compared with the AGEs + NG group (Fig. 2C, E, F and I; all $\mathrm{P}<0.05$ ), and were 8.6-, 9.7- and 10.2-fold higher, respectively, in the AGEs $+\mathrm{HG}+$ Hemin group than in the AGEs $+\mathrm{HG}$ group (Fig. 2D, E, F and J; all $\mathrm{P}<0.05$ ). CrMP exerted selective effects against HO-1 activity. HO-1 protease activity decreased by 25.2 and $10.7 \%$ in the NG + CrMP group and NG + Hemin + CrMP group, respectively, compared with the NG group at $72 \mathrm{~h}$ (Fig. $2 \mathrm{H}$; both $\mathrm{P}<0.05$ ), decreased by 28.7 and $8.1 \%$ in the $\mathrm{AGEs}+\mathrm{NG}+\mathrm{CrMP}$ group and AGEs $+\mathrm{NG}+\mathrm{Hemin}+\mathrm{CrMP}$ group, respectively, compared with the AGEs + NG group (Fig. 2I; both $\mathrm{P}<0.05$ ), and decreased by 24.3 and $10.3 \%$ in the $\mathrm{AGEs}+\mathrm{HG}+\mathrm{CrMP}$ group and AGEs $+\mathrm{HG}+\mathrm{Hemin}+\mathrm{CrMP}$ group, respectively, compared with the AGEs + HG group (Fig. 2J; both $\mathrm{P}<0.05$ ). These results suggested that hemin treatment induced HO-1 expression, and CrMP abolished the effects of hemin. Therefore, a fibroblast model of high HO-1 expression was successfully established.

HO-1 alleviates fibroblast oxidative stress. Hemin treatment for $72 \mathrm{~h}$ inhibited ROS, MDA and $8-\mathrm{OHdG}$ production in the $\mathrm{NG}+$ Hemin group by $36.6,34.3$ and $52.8 \%$, respectively, compared with the $\mathrm{NG}$ group (all $\mathrm{P}<0.05$ ). In addition, 45.6, 36.5 and $61.6 \%$ inhibition was observed in the AGEs $+\mathrm{NG}+$ Hemin group compared with the AGEs + NG group (all $\mathrm{P}<0.05)$, and 50.8, 47.7 and $48.7 \%$ inhibition was observed in the AGEs + HG + Hemin group compared with the AGEs + $\mathrm{HG}$ group (all $\mathrm{P}<0.05$ ). CrMP abolished the effects of hemin. ROS, MDA and 8-OHdG levels in $\mathrm{NG}+$ Hemin + CrMP group were 1.06-, 1.03- and 1.01-fold higher, respectively, than those in the NG group at $72 \mathrm{~h}$, were 1.00-, 1.06- and 1.02-fold higher, respectively, in the AGEs + NG + Hemin + CrMP group than those in the AGEs + NG group, and were 1.02-, 1.01- and 1.01-fold higher, respectively, in the AGEs + $\mathrm{HG}+$ Hemin + CrMP group than those in the AGEs + HG group. These results suggested that the hemin-induced HO-1 expression may alleviate oxidative stress in fibroblasts, but CrMP abolished the effects of hemin (Table I).

HO-1 alleviates the fibroblast inflammatory response. Hemin treatment for $72 \mathrm{~h}$ inhibited TNF- $\alpha$, IL- 6 and IL- $1 \beta$ production in the $\mathrm{NG}+$ Hemin group by $59.1,55.4$ and $56.8 \%$, respectively, compared with the $\mathrm{NG}$ group (all $\mathrm{P}<0.05$ ). In addition, $62.5,44.9$ and $52.4 \%$ inhibition was observed in the AGEs + $\mathrm{NG}+$ Hemin group compared with the AGEs + NG group (all $\mathrm{P}<0.05$ ), and 61.2, 53.7 and $45.4 \%$ inhibition was observed in the AGEs + HG + Hemin group compared with the AGEs + HG group (all $\mathrm{P}<0.05$ ). However, TNF- $\alpha$, IL-6 and IL-1 $\beta$ 


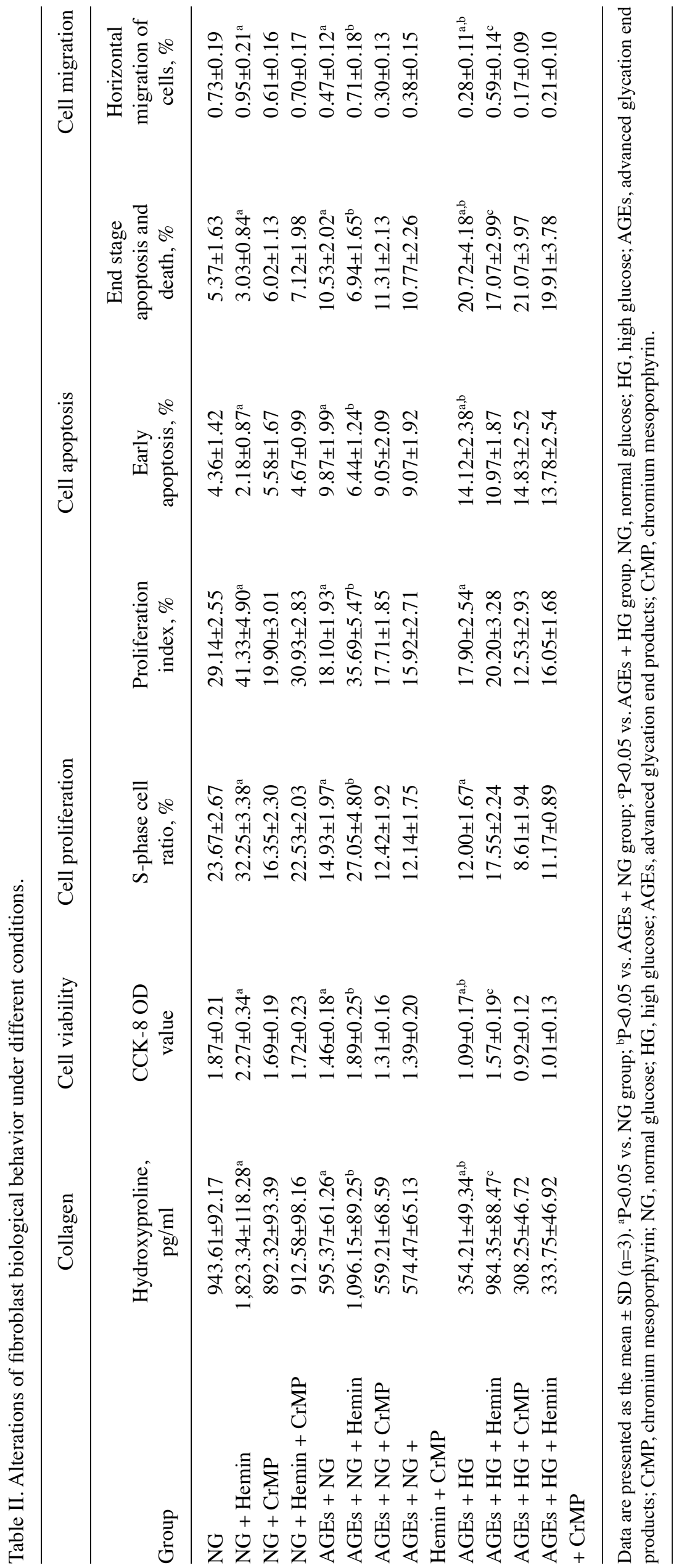



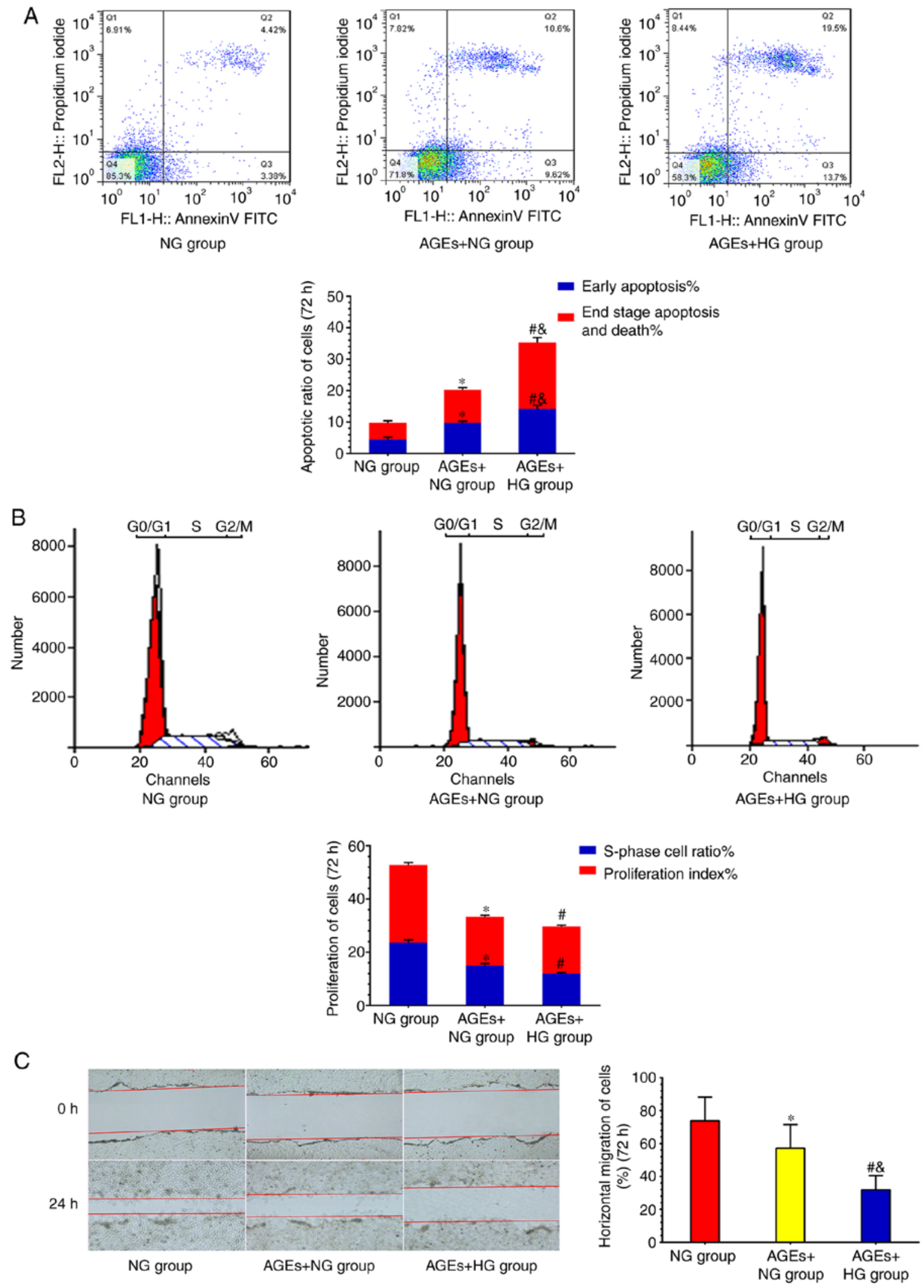

Figure 1. Establishment of the fibroblast biological behavioral disorder model. AGEs (A) increased cell apoptosis and decreased (B) fibroblast proliferation and (C) migration. Additionally, worsened fibroblast biological behavioral disorders were caused by the combination of AGEs and HG. All experiments were performed in triplicate, and the data are presented as the mean $\pm \mathrm{SD}$. ${ }^{*} \mathrm{P}<0.05 \mathrm{NG}$ group vs. AGEs $+\mathrm{NG}$ group; ${ }^{\sharp} \mathrm{P}<0.05 \mathrm{NG}$ group vs. AGEs $+\mathrm{HG}$ group; ${ }^{\&} \mathrm{P}<0.05$ AGEs + NG group vs. AGEs + HG group. NG, normal glucose; HG, high glucose; AGEs, advanced glycation end products.

levels in the NG + Hemin + CrMP group were 1.07-, 1.08- and 1.11-fold higher, respectively, than those in the NG group at $72 \mathrm{~h}$, were 1.06-, 1.02- and 1.08-fold higher, respectively, in the AGEs + NG + Hemin + CrMP group compared with those in the AGEs + NG group, and were 1.06-, 1.03- and 1.05-fold higher, respectively, in the AGEs + HG + Hemin + CrMP 
A

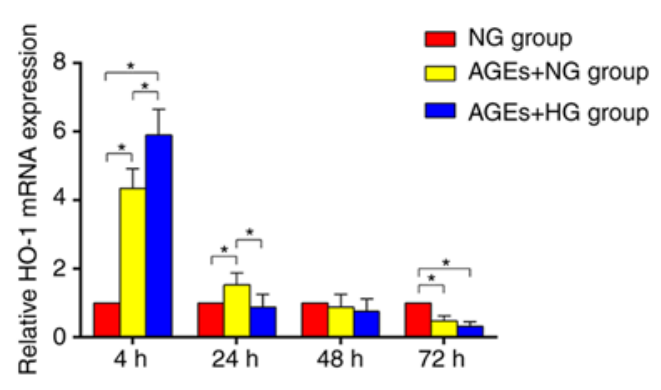

C

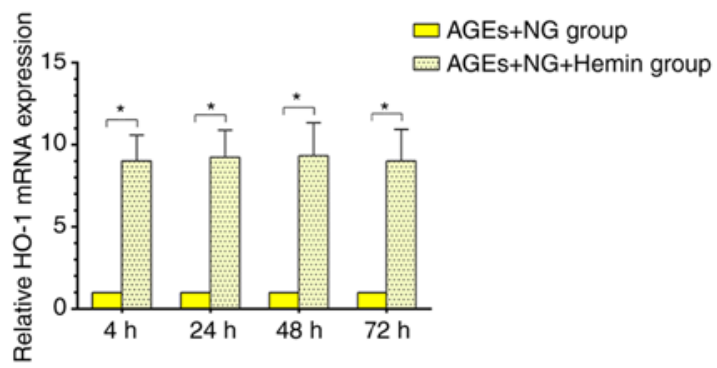

E

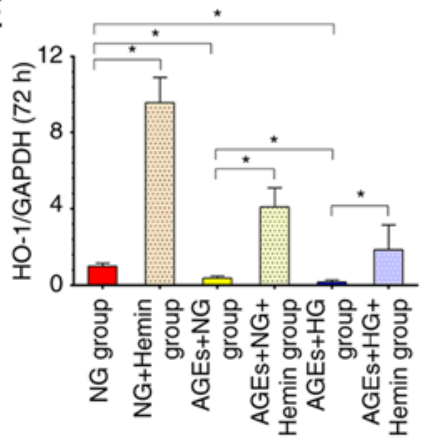

$\mathrm{H}$

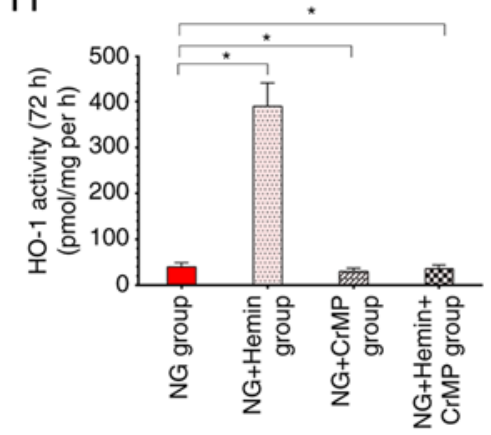

F

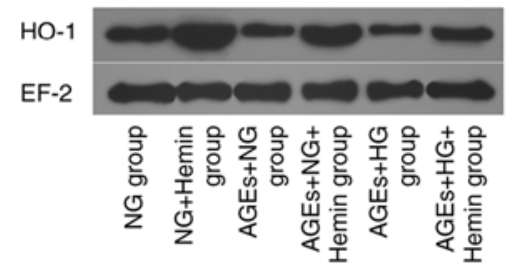

I

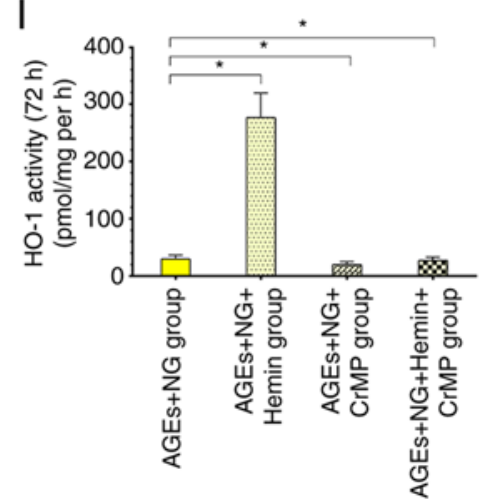

B

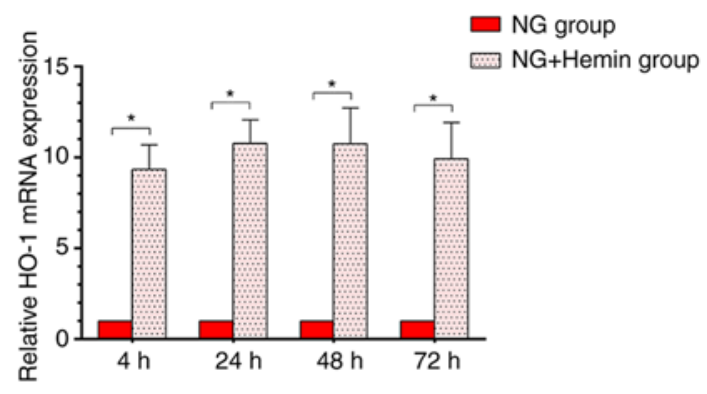

$\mathrm{D}$

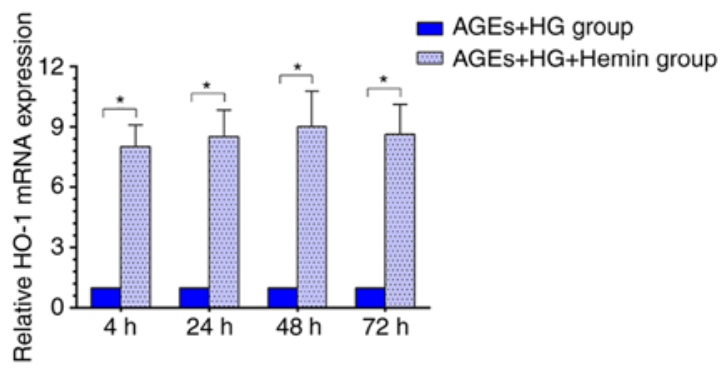

G

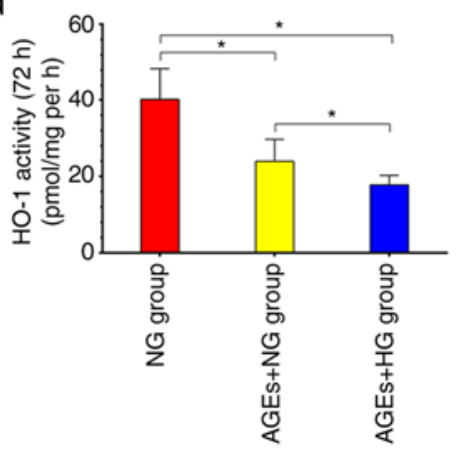

$J$

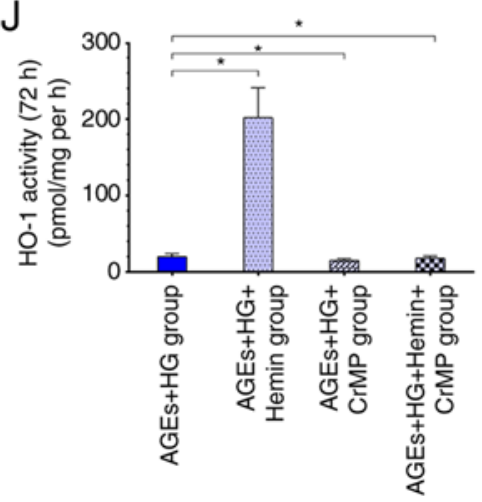

Figure 2. Establishment of the high HO-1 expression model. (A) HO-1 expression exhibited time-dependent alterations. Within 4 h, HO-1 expression was increased, after which it gradually declined and reached the lowest level at $72 \mathrm{~h}$. (B) Hemin induced HO-1 mRNA expression in NG + Hemin group. (C) Hemin induced HO-1 mRNA expression in AGEs + NG + Hemin group. (D) Hemin induced HO-1 mRNA expression in AGEs + HG + Hemin group. (E and F) Hemin induced HO-1 protein expression in the hemin groups, as indicated by western blotting. (G) In the AGES + NG and AGEs + HG groups, the HO-1 activity was lower than that of the NG group. (H) Hemin increased HO-1 activity, and CrMP abolished the effects of hemin in the NG group. (I) Hemin increased HO-1 activity, and CrMP abolished the effects of hemin in the AGEs + NG group. (J) Hemin increased HO-1 activity, and CrMP abolished the effects of hemin in the AGEs + HG group. All experiments were performed in triplicate, and the data are presented as the means \pm SD. ${ }^{*} \mathrm{P}<0.05$. NG, normal glucose; HG, high glucose; AGEs, advanced glycation end products; HO-1, heme oxygenase-1; CrMP, chromium mesoporphyrin.

group compared with those in the AGEs + HG group. These results suggested that the hemin-induced HO-1 expression may alleviate the inflammatory insult in fibroblasts, but CrMP abolished the effects of hemin (Table I).

HO-1 improves fibroblast biological behaviors. Hemin treatment for $72 \mathrm{~h}$ increased fibroblast collagen secretion
$(1823.34 \pm 118.28 \mathrm{pg} / \mathrm{ml})$, cell viability $(2.27 \pm 0.34)$, the S-phase cell ratio $(32.25 \pm 3.38 \%)$, the proliferation index $(41.33 \pm 4.90 \%)$ and the horizontal migration rate $(0.95 \pm 0.21 \%)$ in the $\mathrm{NG}+$ Hemin group compared with the NG group $(943.61 \pm 92.17 \mathrm{pg} / \mathrm{ml}, 1.87 \pm 0.21,23.67 \pm 2.67 \%, 29.14 \pm 2.55 \%$ and $0.73 \pm 0.19 \%$, respectively; all $\mathrm{P}<0.05$ ). Early apoptosis $(2.18 \pm 0.87 \%)$ and end-stage apoptosis and death $(3.03 \pm 0.84 \%)$ 

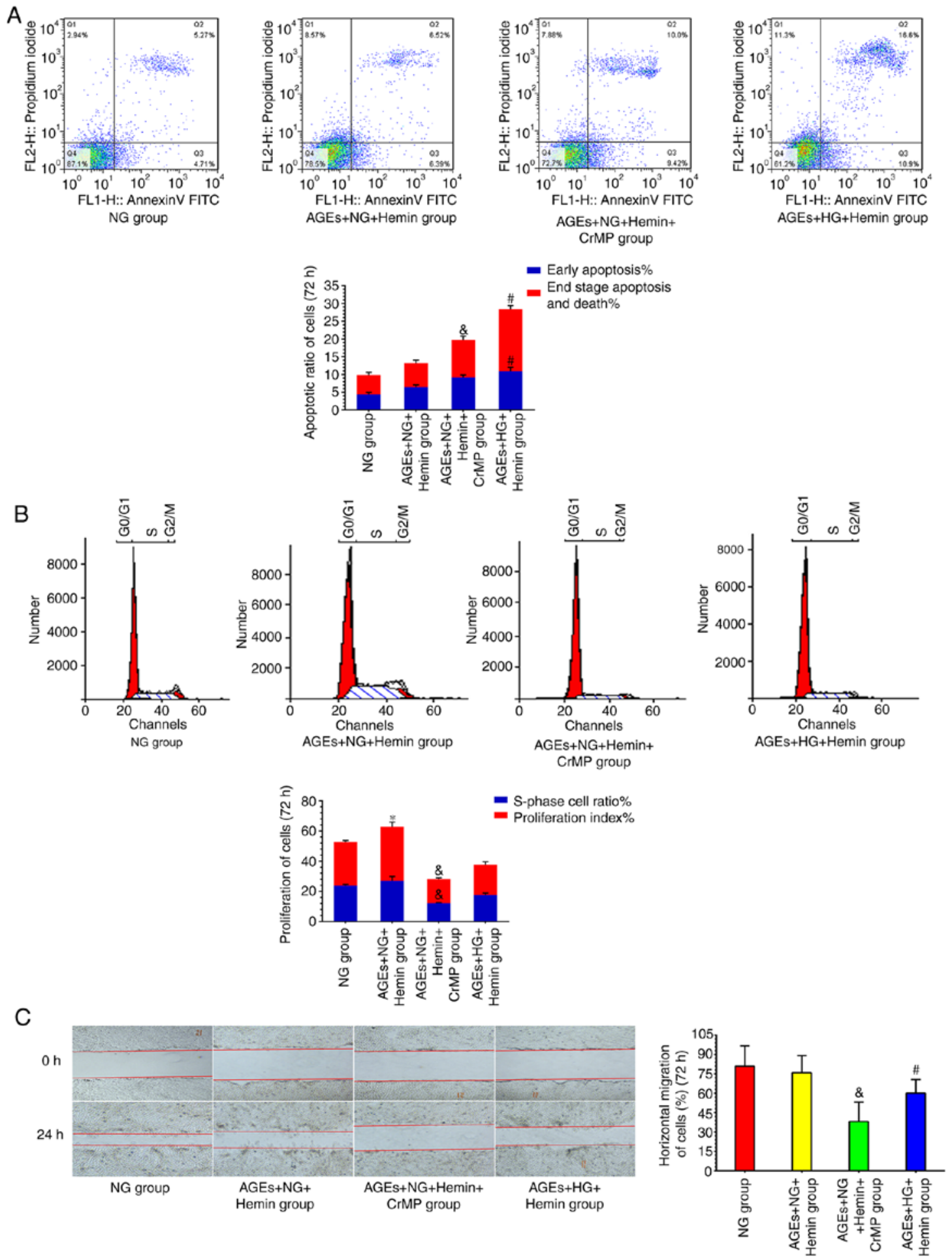

Figure 3. Heme oxygenase-1 expression partially reverses fibroblast biological behavioral disorders. (A) In the AGEs $+\mathrm{NG}+\mathrm{Hemin}$ and AGEs $+\mathrm{HG}+\mathrm{Hemin}$ group, cells apoptosis did not return to the levels of those in NG group. (B) In the AGEs + NG + Hemin group, cell proliferation was higher than that in the NG group. In the AGEs + HG + Hemin group, cell proliferation was lower than that in the NG group. (C) In the AGEs + NG + Hemin and AGEs + HG + Hemin group, cells migration did not return to the levels of those in the NG group. CrMP abolished the effects of hemin. All experiments were performed in triplicate, and the data are presented as the mean $\pm \mathrm{SD}$. ${ }^{*} \mathrm{P}<0.05 \mathrm{NG}$ group vs. AGEs $+\mathrm{NG}+$ Hemin group; ${ }^{\#} \mathrm{P}<0.05 \mathrm{NG}$ group vs. AGEs $+\mathrm{HG}+\mathrm{Hemin}$ group; ${ }^{\text {\& }}<<0.05$ AGEs $+\mathrm{NG}+$ Hemin group vs. AGEs $+\mathrm{NG}+\mathrm{Hemin}+\mathrm{CrMP}$ group.

were decreased in the $\mathrm{NG}+$ Hemin group compared with the NG group $(4.36 \pm 1.42 \%$ and $5.37 \pm 1.63 \%$, respectively; both $\mathrm{P}<0.05)$. Fibroblast collagen secretion $(1096.15 \pm 89.25 \mathrm{pg} / \mathrm{ml})$, cell viability $(1.89 \pm 0.25)$, the S-phase cell ratio $(27.05 \pm 4.80 \%)$, the proliferation index $(35.69 \pm 5.47 \%)$ and the horizontal migration rate $(0.71 \pm 0.18 \%)$ were increased in the AGEs +
$\mathrm{NG}+$ Hemin group compared with the AGEs + NG group $(595.37 \pm 61.26 \mathrm{pg} / \mathrm{ml}, 1.46 \pm 0.18,14.93 \pm 1.97 \%, 18.10 \pm 1.93 \%$ and $0.47 \pm 0.12 \%$, respectively; all $\mathrm{P}<0.05)$. Early apoptosis $(6.44 \pm 1.24 \%)$ and end-stage apoptosis and death $(6.94 \pm 1.65 \%)$ were decreased in the AGEs + NG + Hemin group compared with the AGEs + NG group $(9.87 \pm 1.99 \%$ and $10.53 \pm 2.02 \%$, 
respectively; both $\mathrm{P}<0.05)$. Fibroblast collagen secretion (984.35 $\pm 88.47 \mathrm{pg} / \mathrm{ml})$, cell viability $(1.57 \pm 0.19)$, and the horizontal migration rate $(0.59 \pm 0.14 \%)$ were increased in the AGEs + HG + Hemin group compared with the AGEs + HG group $(354.21 \pm 49.34 \mathrm{pg} / \mathrm{ml}, 1.09 \pm 0.17,12.00 \pm 1.67 \%$, $17.90 \pm 2.54 \%$ and $0.28 \pm 0.11 \%$, respectively) $(\mathrm{P}<0.05)$, and the $\mathrm{S}$-phase cell ratio $(17.55 \% \pm 2.24)$ and proliferation index $(20.20 \pm 3.28 \%)$ were also increased. End-stage apoptosis and death $(17.07 \pm 2.99 \% ; \mathrm{P}<0.05)$ was decreased in the AGEs + $\mathrm{HG}+$ Hemin group compared with the AGEs + HG group $(20.72 \pm 4.18 \%)$ (Table II).

CrMP abolished the effects of hemin. Fibroblast collagen secretion $(912.58 \pm 98.16 \mathrm{pg} / \mathrm{ml})$, cell viability $(1.72 \pm 0.23)$, the S-phase cell ratio $(22.53 \pm 2.03 \%)$, and the horizontal migration rate $(0.70 \pm 0.17 \%)$ were inhibited in the $\mathrm{NG}+$ Hemin + CrMP group compared with the NG group. Early apoptosis $(4.67 \pm 0.99 \%)$ and end-stage apoptosis and death $(7.12 \pm 1.98 \%)$ were increased in the $\mathrm{NG}+$ Hemin + CrMP group compared with the NG group. Fibroblast collagen secretion $(574.47 \pm 65.13 \mathrm{pg} / \mathrm{ml})$, cell viability $(1.39 \pm 0.20)$, the $S$-phase cell ratio $(12.14 \pm 1.75 \%)$, the proliferation index $(15.92 \pm 2.71 \%)$ and the horizontal migration rate $(0.38 \pm 0.15 \%)$ were inhibited in the AGEs + NG + Hemin + CrMP group compared with the AGEs $+\mathrm{NG}$ group. End-stage apoptosis and death $(10.77 \pm 2.26 \%)$ was increased in the AGEs $+\mathrm{NG}+$ Hemin + CrMP group compared with the AGEs + NG group. Fibroblast collagen secretion $(333.75 \pm 46.92 \mathrm{pg} / \mathrm{ml})$, cell viability $(1.01 \pm 0.13)$, the $S$-phase cell ratio $(11.17 \pm 0.89 \%)$, the proliferation index $(16.05 \pm 1.68 \%)$ and the horizontal migration rate $(0.21 \pm 0.10 \%)$ were inhibited in the AGEs + HG + Hemin + CrMP group compared with the AGEs + HG group. Early apoptosis $(13.78 \pm 2.54 \%)$ and end-stage apoptosis and death $(19.91 \pm 3.78 \%)$ were decreased in the AGEs + HG + Hemin + CrMP group compared with the AGEs + HG group (Table II; Fig. S1). Collagen secretion, viability, proliferation, apoptosis and migration are important biological behaviors of fibroblasts (1). The results of the present study suggested that the hemin-induced HO-1 expression may improve the biological behaviors of fibroblasts, but CrMP abolished the effects of hemin.

HO-1 partially reverses fibroblast functional disorders. In the AGEs + NG + Hemin and AGEs + HG + Hemin groups, markers of oxidative stress (ROS, MDA and 8-OHdG) and inflammatory insult (TNF- $\alpha$, IL-6 and IL-1 $\beta$ ) were higher than those in the NG group (Table I). Compared with the NG group, fibroblast collagen secretion, viability and proliferation were increased, the horizontal migration rate was decreased, and the apoptosis rate was increased in the AGEs $+\mathrm{NG}+$ Hemin group (Table II) (Fig. 3). In the AGEs + HG + Hemin group, fibroblast collagen secretion was increased, cell viability, proliferation and the horizontal migration rate were decreased, and the cell apoptosis rate was increased compared with those in the NG group (Table II) (Fig. 3).

The results suggested that in the AGEs $+\mathrm{NG}+$ Hemin group, the hemin-induced HO-1 expression partially restored cellular functions to levels similar to those of the NG group. However, in the AGEs + HG + Hemin group, HO-1 expression hardly restored cellular functions to levels similar to those of the NG group.

\section{Discussion}

DFUs are nonhealing chronic wounds that are a serious complication of diabetes $(1,2)$. AGEs, which are harmful compounds associated with diabetes, induce cell apoptosis, oxidative and inflammatory insults, and previous studies have demonstrated that AGEs result in delayed or impaired wound repair in DFUs (14-16). Various hyperglycemia-induced metabolic and hemodynamic derangements, such as increased AGE deposition, enhance the production of ROS, and stimulate protein kinase $\mathrm{C}$, which may contribute to DFUs (15). AGEs act via their receptor for advanced glycosylation end product and have been implicated in chronic diabetic wounds and inflammation (16). AGEs have been implicated in diabetes-related complications, including diabetic neuropathy, diabetic nephropathy and DFU-related delayed wound healing $(17,18)$.

Diabetes is characterized by increases in oxidative and inflammatory insults $(19,20)$. A previous study indicated that in a HG environment, rat dermal fibroblast biological behavior was disrupted, and oxidative stress indices (ROS and 8-OHdG) were increased (10). In the present study, alterations in fibroblast biological behaviors, oxidative stress and inflammatory insult indices were observed in the presence of AGEs. Oxidative stress (ROS, MDA and 8-OHdG) and inflammatory insult indices (TNF- $\alpha$, IL-6 and IL-1 $\beta$ ) were significantly increased in the present of AGEs, and the biological behaviors of fibroblasts were impaired. Specific alterations were observed, including increased cell apoptosis and decreased collagen synthesis, viability, cell proliferation and migration. AGEs caused oxidative stress, inflammatory insult and fibroblast biological behavioral disorders, and severe fibroblast functional damage was induced by the combination of AGEs and high glucose. High glucose toxicity and AGE deposits are associated with cellular dysfunction, and when combined these factors can cause further damage to the cells $(10,14)$.

Previous studies have demonstrated that oxidative stress and chronic inflammation are involved in the damage that occurs in diabetes $(19,20)$. HO-1 is an antioxidative, anti-inflammatory and cytoprotective enzyme that is expressed as a protective response to stress (6). The HO system can suppress these injuries by generating carbon monoxide, bilirubin/biliverdin and free divalent iron to oppose apoptosis, inflammation and oxidative stress $(6,10)$. Basal $\mathrm{HO}$ activity is maintained by HO-2, while HO-1 is stimulated by a wide variety of physical, chemical and pathophysiological stimuli, including oxidative and inflammatory insults, as well as metabolic and hemodynamic factors, such as high glucose, elevated blood pressure and increased lipid levels $(9,10)$. Therefore, the expression of HO-1 is an important protective response to a wide variety of stress types $(8,9)$. It has been revealed that HO-1 expression is differentially regulated in organs under different disease states (6-10). Our previous study indicated that high glucose could induce HO-1 expression, but this effect was short-lived (10). The present study revealed that in the presence of AGEs, HO-1 expression exhibited a time-dependent alteration.

HO-1 is an inducible isoform and is activated by a variety of stimuli, such as hemin, lipopolysaccharide and $\mathrm{H}_{2} \mathrm{O}_{2}(9)$. In the present study, hemin was used to induce HO-1 expression, and CrMP, which exhibits selective effects against $\mathrm{HO}$ 
activity (11), was used to abolish the effects of hemin. The results demonstrated that hemin markedly induced HO-1 expression. On the other hand, the coadministration of the $\mathrm{HO}$ blocker CrMP and HO inducer hemin abolished the effects of hemin, whereas in the presence of CrMP alone, HO-1 exhibited reduced expression. These results suggested that a high HO-1 expression model was successfully established.

Inducible HO-1 functions in a wide range of processes that may be important in the resolution phase of wound healing, such as the amelioration of oxidative injury and inflammation and protection against cell apoptosis $(8,10)$. Oxidative stress serves an important role in the development of diabetic foot, and the disruption of the redox balance contributes to poor healing $(5,19)$. The present study demonstrated that AGE treatment increased the cellular ROS, MDA and 8-OHdG levels. ROS are common oxidative damage indicators that are highly expressed in diabetic conditions $(4,8)$. MDA is a marker of oxidative stress that is a product of lipid peroxidation, and is involved in the oxidative conversion of polyunsaturated fatty acids. This reaction is the most studied biologically relevant free radical reaction (4). $8-\mathrm{OHdG}$ is a sensitive indicator of oxidative damage to DNA and is increased in diseases, such as diabetes and obesity $(5,21)$. Oxidative stress is one of the causes of cell and tissue damage in diabetes $(19,21)$. It has been indicated that $\mathrm{HO}-1$ exerts protective effects against diabetes-induced oxidative stress, and could decrease MDA and ROS levels (22). The induction of HO-1 with hemin can suppress oxidative stress in diabetic rats $(9,23)$. In the present study, the ROS, MDA and 8-OHdG levels were increased in the presence of AGEs, but hemin treatment notably reduced ROS, MDA and 8-OHdG levels. On the other hand, the coadministration of CrMP and hemin abolished the effects of hemin, whereas treatment with CrMP alone increased the levels of ROS, MDA and 8-OHdG. Therefore, the results indicated that HO-1 alleviated AGE-induced oxidative injury in fibroblasts.

Inflammatory insults serve an important role in the development of diabetic foot, and several proinflammatory cytokines have been indicated to be significantly elevated in diabetes $(19,24)$. It has been demonstrated that hemin induces the HO-1-mediated suppression of proinflammatory cytokines (TNF- $\alpha$, IL-6 and IL-1 $\beta$ ), which in turn activates the JNK and $\mathrm{NF}-\kappa \mathrm{B}$ pathways, leading to a vicious circle that exacerbates diabetic complications (7). The effects of concomitantly activating the $\mathrm{HO}$ system with hemin treatment on these cytokines were investigated. In the present study, the levels of TNF- $\alpha$, IL- 6 and IL-1 $\beta$ were markedly elevated in the presence of AGEs. Interestingly, hemin significantly abated the increases in the levels of TNF- $\alpha$, IL- 6 and IL-1 $\beta$. On the other hand, the coadministration of CrMP and hemin abolished the effects of hemin, whereas treatment with CrMP alone increased the levels of TNF- $\alpha$, IL- 6 and IL- $1 \beta$. Therefore, it was revealed that HO-1 alleviated fibroblast inflammatory insults caused by AGEs.

Fibroblasts act as major repair cells in skin wounds (25). Fibroblasts isolated from DFUs are likely to be senescent and exhibit slow, declining proliferative responses $(1,25)$. The present study demonstrated that fibroblast biological functions were impaired in the presence of AGEs. The specific effects included increased apoptosis and decreased collagen synthesis, viability, proliferation and migration, with severe functional damage being caused by the combination of AGEs and HG conditions. In normal skin, type I and III collagen coexist in a ratio of $3.5: 1(1,26)$. In certain pathological conditions, such as diabetic wound healing, AGE deposition, excessive inflammatory reactions and enhanced oxidative stress damage, the proportion of type III collagen is increased, and excessive type III collagen results in scar hyperplasia or fibrosis $(1,26)$. In the present study, fibroblast collagen secretion decreased in the presence of AGEs, while HO-1 increased fibroblast collagen secretion and decreased the inflammatory response and oxidative stress injury. HO-1 may reduce fibroblast functional disorders induced by AGEs and accelerate the healing of diabetic wounds by improving fibroblast biological behaviors and reducing oxidative stress and inflammatory insults. Further animal experiments on skin collagen components and elucidation of the associated mechanisms are required.

Delayed diabetic wound healing is associated with impaired fibroblast biological behaviors to a certain extent $(1,25)$. Keyse and Tyrrell (27) first suggested the cytoprotective role of HO-1. Impaired wound healing in diabetic mice may be associated with delayed $\mathrm{HO}-1$ upregulation, and $\mathrm{HO}-1$ gene transfer has been indicated to improve wound healing $(8,28)$. It was observed that the biological behaviors of fibroblasts were impaired in the presence of AGEs for $72 \mathrm{~h}$. However, the HO-1 inducer hemin increased fibroblast collagen synthesis and cell viability, improved proliferation and migration and decreased cell apoptosis. On the other hand, the coadministration of CrMP and hemin abolished the effects of hemin, whereas treatment with CrMP alone exacerbated the disordered fibroblast biological behaviors. It was hypothesized that HO-1 alleviated the disordered fibroblast biological behavior caused by AGEs. HO-1 is a protective enzyme that is highly expressed in response to stress (6-8). In the present study, the antioxidative, anti-inflammatory and cytoprotective effects of HO-1 were investigated. The results suggested that HO-1 alleviated the fibroblast functional disorders induced by AGEs, but it was difficult to reverse the functional disorders and restore cellular functions to normal levels.

In conclusion, the results of the present study indicated that compared with normal glucose conditions, AGEs induced fibroblast oxidative stress, inflammatory insult and biological behavioral disorders, and severe cell damage was caused by the combination of AGEs and HG conditions. Hemin treatment induced HO-1 expression, reduced oxidative stress (ROS, MDA and 8-OHdG) and inflammatory insult indicators (TNF- $\alpha$, IL- 6 and IL-1 $\beta$ ) and improved cell biological behaviors, including increased cellular collagen synthesis, viability, proliferation and migration and decreased cell apoptosis. These findings suggested that HO-1 may reduce fibroblast functional disorders and accelerate the healing of diabetic wounds by improving fibroblast biological behaviors and reducing oxidative stress and inflammatory responses. Increasing HO-1 expression may represent a feasible strategy for improving diabetic wound healing.

\section{Acknowledgements}

Not applicable. 


\section{Funding}

The present study was supported by grants from National Natural Science Foundation of China (grant no. 81801757), Natural Science Foundation of Guangdong Province (grant no. 2018A030310322), Guangdong Basic and Applied Basic Research Foundation (grant no. 2019A1515012051) and Guangdong Medical Research Foundation (grant no. A2018106).

\section{Availability of data and materials}

The datasets used and/or analyzed during the current study are available from the corresponding author on reasonable request.

\section{Authors' contributions}

QLL and RMG confirm the authenticity of all the raw data. QLL, SYL, RMG, QWL, LSS and YZ conceived and designed the study, acquired, analyzed and interpreted data. QLL and SYL drafted and revised the manuscript for important intellectual content. QWL and LSS performed literature search. YZ and RMG edited the manuscript. All authors have read and approved the final version of the manuscript.

\section{Ethics approval and consent to participate}

Not applicable.

\section{Patient consent for publication}

Not applicable.

\section{Competing interests}

The authors declare that they have no competing interests.

\section{References}

1. Maione AG, Smith A, Kashpur O, Yanez V, Knight E, Mooney DJ, Veves A, Tomic-Canic M and Garlick JA: Altered ECM deposition by diabetic foot ulcer-derived fibroblasts implicates fibronectin in chronic wound repair. Wound Repair Regen 24: 630-643, 2016.

2. Guo Y, Lin C, Xu P, Wu S, Fu X, Xia W and Yao M: AGEs induced autophagy impairs cutaneous wound healing via stimulating macrophage polarization to M1 in diabetes. Sci Rep 6: 36416, 2016.

3. Rajaobelina K, Helmer C, Vélayoudom-Céphise FL, Nov S, Farges B, Pupier E, Blanco L, Hugo M, Gin H and Rigalleau V: Progression of skin autofluorescence of AGEs over 4 years in patients with type 1 diabetes. Diabetes Metab Res Rev 33: e2917, 2017.

4. Chen Y, Wu Y, Gan X, Liu K, Lv X, Shen H, Dai G and Xu H: Iridoid glycoside from Cornus officinalis ameliorated diabetes mellitus-induced testicular damage in male rats: Involvement of suppression of the AGEs/RAGE/p38 MAPK signaling pathway. J Ethnopharmacol 194: 850-860, 2016.

5. Al-Aubaidy HA and Jelinek HF: Oxidative DNA damage and obesity in type 2 diabetes mellitus. Eur J Endocrinol 164: 899-904, 2011.

6. Ndisang JF: Role of heme oxygenase in inflammation, insulin-signalling, diabetes and obesity. Mediators Inflamm 2010: 359732, 2010.

7. Ndisang JF and Jadhav A: Hemin therapy improves kidney function in male streptozotocin-induced diabetic rats: Role of the heme oxygenase/atrial natriuretic peptide/adiponectin axis. Endocrinology 155: 215-229, 2014.

8. Chen QY, Wang GG, Li W, Jiang YX, Lu XH and Zhou PP: Heme oxygenase-1 promotes delayed wound healing in diabetic rats. J Diabetes Res 2016: 9726503, 2016.
9. Ndisang JF and Jadhav A: Up-regulating the hemoexygenase system enhances insulin sensitivity and improves glycose metabolism in insulin-resistant diabetes in Goto-Kakizaki rats. Endocrinology 150: 2627-2636, 2009

10. Li QL, Guo RM, Zhao K, Lin DZ, Ye XM and Chen LH: Effects of heme oxygenase-1 expression on oxidative injury and biological behaviours of rat dermal fibroblasts. J Wound Care 27: 780-789, 2018.

11. Reis WL, Biancardi VC, Son S, Antunes-Rodrigues J and Stern JE: Enhanced expression of heme oxygenase-1 and carbon monoxide excitatory effects in oxytocin and vasopressin neurones during water deprivation. J Neuroendocrinol 24: 653-663, 2012.

12. Livak KJ and Schmittgen TD: Analysis of relative gene expression data using real-time quantitative PCR and the 2 (-Delta Delta C(T)) method. Methods 25: 402-408, 2001.

13. Xue SN, Lei J, Yang C, Lin DZ and Yan L: The biological behaviors of rat dermal fibroblasts can be inhibited by high levels of MMP9. Exp Diabetes Res 2012: 494579, 2012

14. Okano Y, Masaki H and Sakurai H: Dysfunction of dermal fibroblasts induced by advanced glycation end-products (AGEs) and the contribution of a nonspecific interaction with cell membrane and AGEs. J Dermatol Sci 29: 171-180, 2002.

15. Yamagishi S, Maeda S, Matsui T, Ueda S, Fukami K and Okuda S: Role of advanced glycation end products (AGEs) and oxidative stress in vascular complications in diabetes. Biochim Biophys Acta 1820: 663-671, 2012.

16. Dong MW, Li M, Chen J, Fu TT, Lin KZ, Ye GH, Han JG, Feng XP, Li XB, Yu LS and Fan YY: Activation of $\alpha 7 n$ AChR Promotes Diabetic Wound Healing by Suppressing AGE-Induced TNF- $\alpha$ Production. Inflammation 39: 687-699, 2016.

17. $\mathrm{Hu} \mathrm{H}$, Jiang $\mathrm{H}$, Ren $\mathrm{H}, \mathrm{Hu} \mathrm{X}$, Wang $\mathrm{X}$ and Han C: AGEs and chronic subclinical inflammation in diabetes: disorders of immune system. Diabetes Metab Res Rev 31: 127-137, 2015.

18. Tesch G, Sourris KC, Summers SA, McCarthy D, Ward MS, Borg DJ, Gallo LA, Fotheringham AK, Pettit AR, Yap FY, et al: Deletion of bone-marrow-derived receptor for AGEs (RAGE) improves renal function in an experimental mouse model of diabetes. Diabetologia 57: 1977-1985, 2014.

19. Vairamon SJ, Babu M and Viswanathan V: Oxidative stress markers regulating the healing of foot ulcers in patients with type 2 diabetes. Wounds 21: 273-279, 2009 .

20. Ingram JR, Cawley S, Coulman E, Gregory C, Thomas-Jones E, Pickles T, Cannings-John R, Francis NA, Harding K, Hood K and Piguet V: Levels of wound calprotectin and other inflammatory biomarkers aid in deciding which patients with a diabetic foot ulcer need antibiotic therapy (INDUCE study). Diabet Med 35: 255-261, 2018.

21. Zheng F, Lu W, Jia C, Li H, Wang Z and Jia W: Relationships between glucose excursion and the activation of oxidative stress in patients with newly diagnosed type 2 diabetes or impaired glucose regulation. Endocrine 37: 201-208, 2010.

22. Song Y, Huang L and Yu J: Effects of blueberry anthocyanins on retinal oxidative stress and inflammation in diabetes through Nrf2/HO-1 signaling. J Neuroimmunol 301: 1-6, 2016.

23. Ndisang JF and Jadhav A: Heme oxygenase system enhances insulin sensitivity and glucose metabolism in streptozotocin-induced diabetes. Am J Physiol Endocrinol Metab 296: E829-E841, 2009.

24. Van Asten SA, Nichols A, La Fontaine J, Bhavan K, Peters EJ and Lavery LA: The value of inflammatory markers to diagnose and monitor diabetic foot osteomyelitis. Int Wound J 14: 40-45, 2017

25. Berlanga-Acosta J, Mendoza-Mari Y, Martínez MD, Valdés-Perez C, Ojalvo AG and Armstrong DG: Expression of cell proliferation cycle negative regulators in fibroblasts of an ischemic diabetic foot ulcer. A clinical case report. Int Wound J 10: 232-236, 2013.

26. Davison-Kotler E, Marshall WS and García-Gareta E: Sources of collagen for biomaterials in skin wound healing. Bioengineering (Basel) 6: 56, 2019.

27. Keyse SM and Tyrrell RM: Heme oxygenase is the major 32-kDa stress protein induced in human skin fibroblasts by UVA radiation, hydrogen peroxide, and sodium arsenite. Proc Natl Acad Sci USA 86: 99-103, 1989.

28. Grochot-Przeczek A, Lach R, Mis J, Skrzypek K, Gozdecka M, Sroczynska P, Dubiel M, Rutkowski A, Kozakowska M, Zagorska A, et al: Heme oxygenase-1 accelerates cutaneous wound healing in mice. PLoS One 4: e5803, 2009.

This work is licensed under a Creative Commons Attribution-NonCommercial-NoDerivatives 4.0 International (CC BY-NC-ND 4.0) License. 